\title{
Histidinaemia: a Child and His Family
}

\author{
A. R. R. CAIN and J. B. HOLTON \\ From the Bristol Royal Hospital for Sick Children, and Department of Pathology, Southmead Hospital, Bristol
}

Histidinaemia, an inherited disorder of histidine metabolism, was first described by Ghadimi, Partington, and Hunter in 1961. The principal metabolic pathway for histidine is through urocanic acid and formiminoglutamic acid (FIGLU) to glutamic acid (Fig. 1). Zannoni and La Du (1963) demonstrated that histidase, the enzyme necessary for the conversion of histidine to urocanic acid, was absent from skin homogenates of patients with histidinaemia. The absence of histidase usually leads to the breakdown of histidine by an alternative pathway, to imidazolepyruvic acid, imidazoleacetic acid, and imidazolelactic acid.

The imidazolepyruvic acid thus formed is excreted in the urine and gives a positive result with the 'Phenistix'^ and ferric chloride tests (Auerbach, DiGeorge, Baldridge, Tourtellotte, and Brigham, 1962; Barger and Stewart, 1926). The majority of cases of histidinaemia have been discovered by this means, and in many this has led to a presumptive diagnosis of phenylketonuria. Davies and Robinson (1963) described a boy in whom the urinary ferric chloride test only became positive after a histidine load. We report here another patient in whom the ferric chloride test was negative and in whom the excretion of abnormal imidazole compounds was undetectable by chromatographic means, even after

Received May 15, 1967.

* Ames Company. a histidine load. However, there is biochemical evidence for a defect in histidase activity, and detailed family studies suggest that the child is homozygous for the abnormal autosomal recessive gene.

\section{Methods}

Chromatography of amino acids and imidazole compounds. Urine was examined by two-dimensional paper chromatography to detect amino acids and unusual imidazole compounds. Urine was desalted using Zeokarb 225 . (Smith, 1958a). The first solvent system was butanol, acetic acid, water followed by butanol, pyridine, water. Chromatograms were stained with ninhydrin reagent to detect amino acids and Pauly's reagent for imidazole compounds. Solvents and staining reagents were prepared and used as described by Smith (1958b).

Amino acids were estimated in plasma following ion exchange chromatography, using a Technicon AminoAcid Analyser. For this technique $1 \mathrm{ml}$. plasma was added to $5 \mathrm{ml}$. cool sulphosalicylic acid $(3 \%)$. After 30 minutes the protein precipitate was removed by centrifugation and the clear supernatant was evaporated to dryness at less than $40^{\circ} \mathrm{C}$. The residue was dissolved in $1 \mathrm{ml} .0 \cdot 1 \mathrm{~N}-\mathrm{HCl}$, which contained $0.1 \mu$ mole of norleucine as an internal standard, and then applied to the ion exchange column. This method of sample preparation gave separations of all the principal amino acids except serine, threonine, and glutamine, which were not estimated.

Quantitative estimations of amino acids in urine were performed by a similar procedure, using the Amino Acid Analyser. The volume of urine was calculated accor-

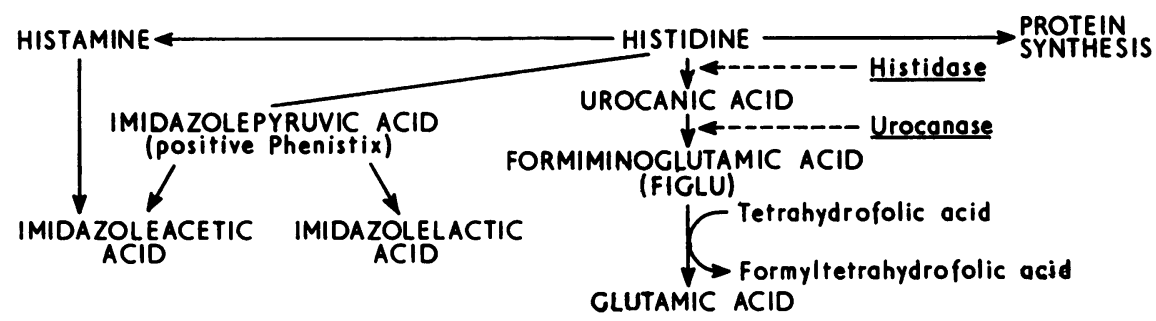

FIG. 1.-Pathways of normal histidine metabolism. 
ding to the creatinine concentration and was usually between 0.2 and $0.4 \mathrm{ml}$. The small aliquot was made alkaline and evaporated to dryness in a vacuum desiccator to remove ammonia. The sample was applied in $0 \cdot 1 \mathrm{~N}-\mathrm{HCl}$ containing internal standard, as in the plasma method.

Histidine loading tests. All tests were carried out after an overnight fast. Adults were asked to drink sufficient fluids to maintain a good urine flow. L-histidine ( $15 \mathrm{~g}$.) was dissolved in orange juice and was drunk after a fasting venous blood sample had been obtained. Further blood was taken one hour and two hours after the histidine load. Histidine was estimated on the plasma of all three specimens.

For children, water $(2 \mathrm{ml} . / \mathrm{kg}$.) was given every half hour from 1 hour before to 3 hours after giving histidine. Histidine (100 mg. $/ \mathrm{kg}$.) was given to the child dissolved in orange juice. Urine was collected for 5 hours after the histidine load and venous blood was obtained fasting and 3 hours after the histidine. Histidine was estimated on plasma and urine, and paper chromatography was carried out on the urine.

Formiminoglutamic acid was estimated in urine by a modification of the method of Lewis and Moore (1962). Urine imidazolepyruvic acid was determined as its enol-borate complex, an adaptation of the technique of Baldridge and Greenberg (1963) for estimation of histidine by conversion to imidazolepyruvic acid. Urine was added to borate-arsenate buffer at $p \mathrm{H} 7 \cdot 8$ and the absorbance of the imidazolepyruvic acid enol-borate complex was read at $292 \mathrm{~m} \mu$ against a blank containing urine in arsenate solution alone at $\mathrm{pH} 7 \cdot 8$.

Skin histidase. Histidase activity was estimated in homogenates of human stratum corneum by the method of Zannoni and La Du (1963).

Sweat urocanic acid. Sweat was collected after pilocarpine iontophoresis using the E.M.S.* Sweat Test Unit, as described by McKendrick (1962). The filter paper was eluted with distilled water and the absorption spectrum of the eluate measured against a water blank in the Unicam SP 800 spectrophotometer.

\section{Case Report}

This male infant was born at 38 weeks' gestation after the removal of a Shirodkar suture at 36 weeks and subsequent surgical induction of labour. Birthweight was $2 \cdot 42 \mathrm{~kg}$., but there were no particular neonatal problems.

He was referred to the out-patient department at 9 months, because of recurrent chest infections which had occurred at $2,3,8$, and 9 months. There was also a suggestion that he had a poor response to sound. On examination he weighed $8.9 \mathrm{~kg}$., his height was $70 \mathrm{~cm}$., and his head circumference $45 \cdot 7 \mathrm{~cm}$. There were no abnormal clinical findings.

At $11 \frac{1}{2}$ months he was examined in a hearing assessment clinic where he was found to have a normal response to sounds and to be able to locate pure tones

* Electro Medical Supplies of London. at 40 decibels from 1000 to $4000 \mathrm{c} / \mathrm{s}$. He was saying several words.

At 18 months he was referred again because of three convulsions, one of which had been associated with pyrexia. The fits had been grand mal in type and of short duration. A further history revealed that he had sat alone at 10 months, crawled at 12 months, and walked by himself at 13 months. There was a family history of fits on both sides, though not in either parent. The only other feature was that he had developed considerable pica over a period of some months. Clinical examination was again normal except for pallor. He had light brown hair and brown eyes.

Investigations. A skull $x$-ray film was normal, the cranial capacity being $1228 \mathrm{ml}$. which is on the 80th centile for his age. His bone age was retarded at the 9-month level and was well below the 10th centile for his age. An EEG was normal. Hb $7 \cdot 7$ g. $/ 100 \mathrm{ml}$., a blood film showing microcytosis and hypochromia, the platelets and white cells being normal. The serum iron was $20 \mu \mathrm{g} . / 100 \mathrm{ml}$. and the blood lead $12 \mu \mathrm{g} . / 100 \mathrm{ml}$. A urinary amino acid chromatogram showed a heavy histidine spot. Plasma amino acid analysis revealed a histidine level of $8 \mathrm{mg} . / 100 \mathrm{ml}$.; the proline level of $5 \cdot 7$ $\mathrm{mg} . / 100 \mathrm{ml}$. was just above the upper limit of the normal range for his age-group. Subsequent proline levels were normal.

He was seen twice by a psychologist, once with his mother, once in the ward. He tended to be timid and slow but was functioning at his age level. He scribbled, built a tower of 3 bricks, and did the Terman-Merrill form board correctly. A dozen or so rather indistinct words were heard but no sentences, though he was said to know about 50 words.

Investigation of histidinaemia. At 20 months he was admitted to hospital for investigation of the histidinaemia. Two fasting blood histidines were $5 \cdot 1$ and $4.9 \mathrm{mg}$. $/ 100 \mathrm{ml}$., the normal range determined in this laboratory being $0.5-1.8 \mathrm{mg}$. $/ 100 \mathrm{ml}$. for children aged 9 months to 2 years, and $1 \cdot 0-2 \cdot 3 \mathrm{mg}$. $/ 100 \mathrm{ml}$. for adults. A histidine value obtained 2 hours after a midday meal was $6.1 \mathrm{mg} . / 100 \mathrm{ml}$., compared with two controls, in children of similar age, of 1.5 and $1.0 \mathrm{mg} . / 100 \mathrm{ml}$. 24-hour urinary histidine excretion was increased in comparison with two controls from $1 \frac{1}{2}$ to 4 times the normal value (Table I).

A histidine load was then given to the patient and the two controls. The results (Table II) show a significantly greater increase of the plasma level and urinary excretion of histidine in the patient, compared with the controls. The complete absence of FIGLU, even after the histidine load, and the increased excretion of imidazolepyruvic acid were consistent with a defect in the main pathway of histidine metabolism. The localization of this block at the level of histidase was shown by the absence of enzyme activity in the skin and the inability to secrete urocanic acid in the sweat (Fig. 2).

Family studies. His mother, father, and older brother had normal fasting plasma histidine levels. The 


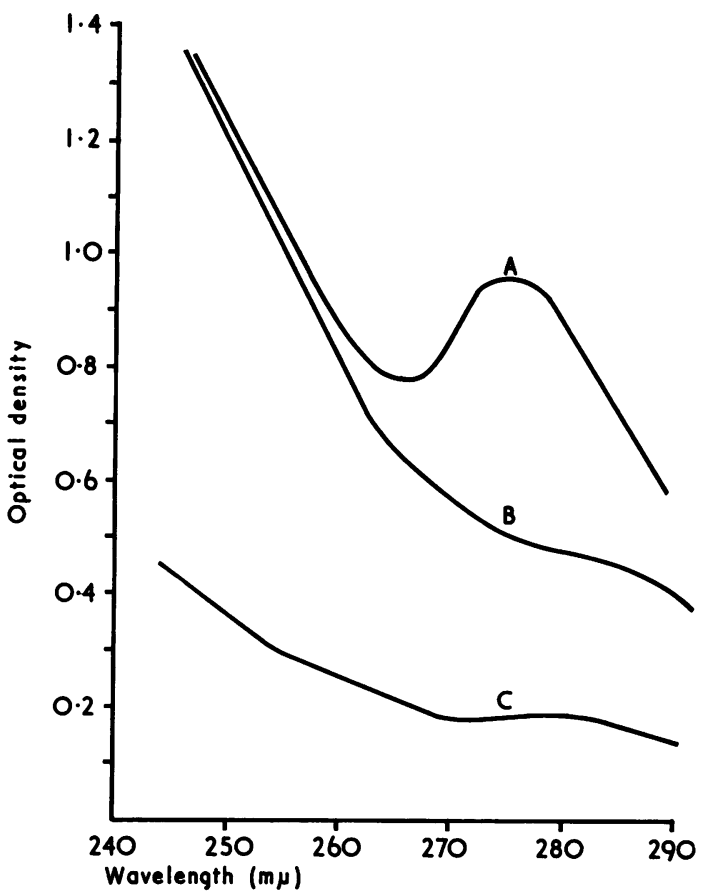

FIG. 2.-Absorption spectrum of diluted sweat to detect the peak for urocanic acid at $275 \mathrm{~m} \mu$.

(A) Sweat from a normal person. (B) Sweat from the patient. (C) $A$ blank consisting of filter paper washings.

youngest sib had a plasma histidine of $4.5 \mathrm{mg} . / 100 \mathrm{ml}$. at 5 days and of $1.2 \mathrm{mg} . / 100 \mathrm{ml}$. at 6 months.

Skin histidase activity was estimated in 10 members of the family, including both parents and all four grandparents (Fig. 3). His father, paternal grandmother, maternal grandfather, and maternal uncle all had levels below the normal range but his mother had a normal level.

A histidine load was given to both parents (Fig. 4). His mother produced a 2-hour plasma histidine level greater than 2 SD above the normal controls, while his father gave a normal result.
TABLE I

Urinary Histidine Excretion (mg./24 hr.)

\begin{tabular}{|c|c|c|c|c|c|}
\hline & & & & Volume (ml.) & Histidine (mg.) \\
\hline $\begin{array}{ll}\text { Patient } & \frac{1}{2} \\
\text { Control } & \frac{1}{2}\end{array}$ & $\begin{array}{l}\cdots \\
\cdots \\
\cdots\end{array}$ & $\begin{array}{l}\ddot{*} \\
\ddot{*}\end{array}$ & $\begin{array}{l}\ldots \\
\ldots \\
\ldots\end{array}$ & $\begin{array}{l}112 \\
120 \\
230 \\
100\end{array}$ & $\begin{array}{r}79 \\
109 \cdot 2 \\
26 \cdot 4 \\
45 \cdot 4\end{array}$ \\
\hline
\end{tabular}

Progress. The patient has had two further fits, i.e. 5 in all, but none since the age of 2 years. His iron-deficient anaemia responded to oral ferrous sulphate, his latest $\mathrm{Hb}$ being $11.4 \mathrm{~g} / 100 \mathrm{ml}$.

The effects of a low histidine diet on plasma histidine levels and growth were determined. The source of amino acids was low histidine 'Albumaid'^. At first he was given $60 \mathrm{mg}$. histidine $/ \mathrm{kg}$. day, but there was no fall in his plasma histidine. His intake of histidine was reduced to $40 \mathrm{mg}$. $/ \mathrm{kg}$. day but the plasma level $(6.8 \mathrm{mg}$./ $100 \mathrm{ml}$.) showed no significant fall. In view of the poor response to this diet and the difficulty of maintaining his morale it was stopped after a total time of 11 months. Three months later his plasma histidine was $7.5 \mathrm{mg}$./ $100 \mathrm{ml}$.

He has always been of small stature but while he was on the low histidine diet his height centile decreased from the 10th to below the 3rd centile. Since stopping the diet he has regained height to the 10th centile. There has been no change in his weight which has remained on the 10th centile. His bone age gradually improved from well below the 10th centile at 20 months to about the 15th centile at the age of 41 months.

Recently it has been noted that many of his teeth have become carious, but there are none of the tooth abnormalities noted by Berlow, Arends, and Harries (1965).

Intellectual development has remained within normal limits, a rough assessment at 20 months showing no significant retardation. A more detailed assessment at 32 months showed that he had developed to the $2 \frac{1}{2}$-yearold level in general, that locomotor and drawing development were within normal limits, and that intellectual development was up to $2 \frac{1}{2}$ years. Speech and visual motor development were at the 2-year-old level. A third assessment at 39 months showed him to be progressing

* Hospital Laboratory Supplies Ltd., Liverpool.

TABLE II

Histidine Load Test

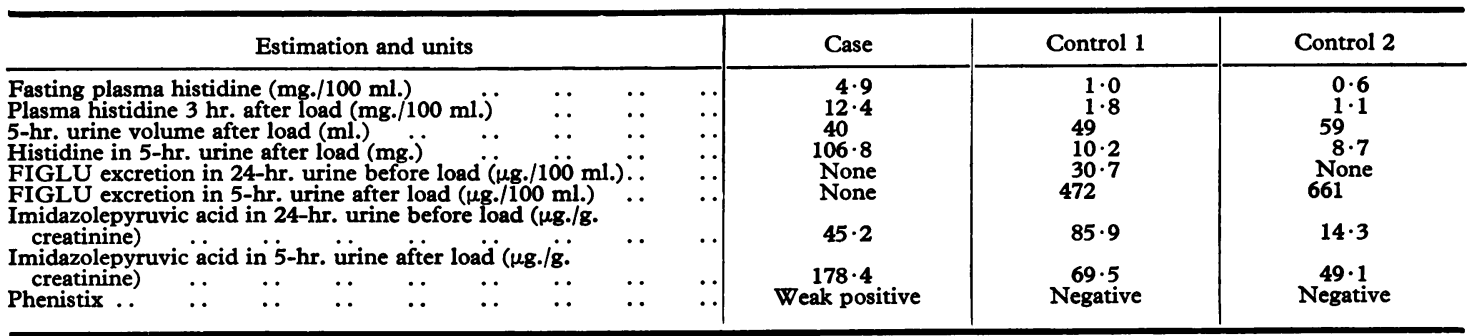




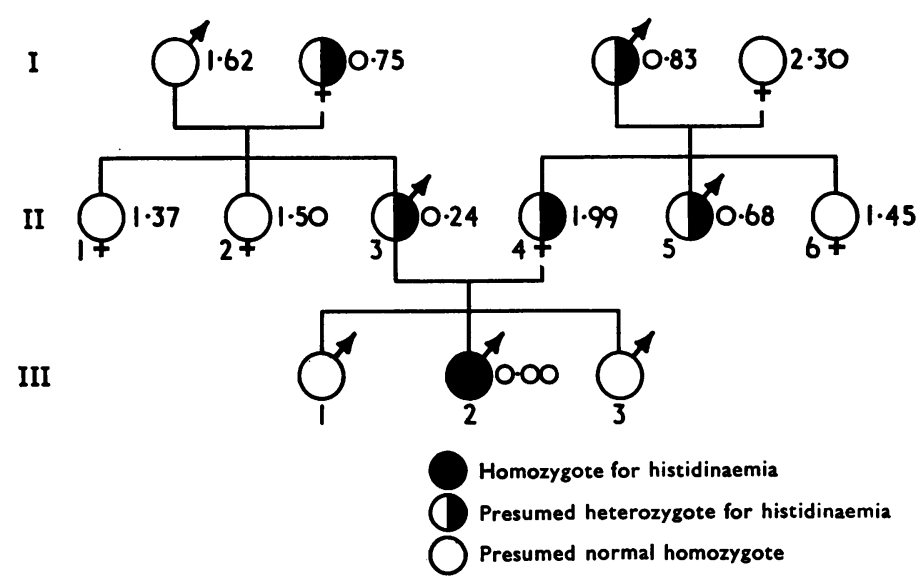

FIG. 3.-Skin histidase in the histidinaemic child and his family ( $\mu$ moles urocanic acid formed per g. skin per hour). Normal values are $1 \cdot 4$ to $2 \cdot 7$ units for adult males and $1 \cdot 0$ to $2 \cdot 7$ for adult females.

appropriately to his age, and speech development had improved to that of a 3-year-old, intellectual development being at 2 years 9 months and visual motor development at $2 \frac{1}{2}$ years. It was thought that the slight retardation in intellectual and visual motor development reflected the level at which he will intellectually function, namely as a child of below average intelligence but within normal limits for schooling purposes. A rough IQ on the Terman-Merrill intelligence scale was $\mathbf{8 6}$.

\section{Discussion}

Incidence. $\mathrm{La} \mathrm{Du} \mathrm{(1966)} \mathrm{has} \mathrm{written} \mathrm{an}$ excellent review of the present state of knowledge about histidinaemia and 15 of the published cases are discussed there. Woody, Snyder, and Harris (1965) and Clarance and Bowman (1966) have described further cases but the three sibs described by Woody et al. do not fit into the generally accepted pattern of the disease, particularly as they have normal skin histidase activity. Including our patient, there have been 23 cases reported over the six-year period since Ghadimi and his colleagues first described the condition, and only 10 of these have been described in detail. Admittedly other cases are known, but, even so, histidinaemia is most probably rare. As the 'Phenistix' test does not detect all cases of histidinaemia the true incidence will not be known until population screening for histidinaemia is carried out. In addition, the introduction of screening tests for phenylketonuria which measure phenylalanine specifically will reduce further the likelihood of detecting cases of histidinaemia.

Clinical findings. There is little homogeneity of presentation in cases of histidinaemia, and it is of

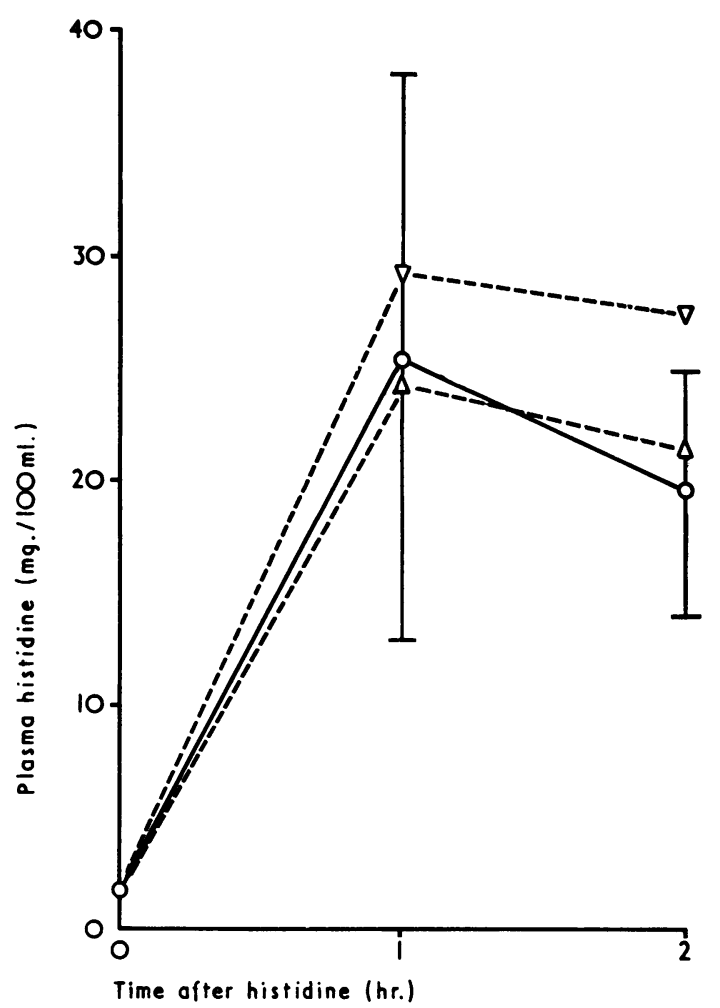

FIG. 4.-Histidine loading test in the parents of the histidinaemic child.

O Mean value determined on 10 control adults. The vertical lines show the range $( \pm 2 S D), \quad \nabla$ The mother. $\triangle$ The father. 
interest to compare our patient with those previously described. The spectrum of clinical manifestation varies from complete normality to one of gross mental retardation and congenital malformation. Many of the cases are associated with speech defect though this is often difficult to distinguish from the general retardation when this is present. Our patient, that of Davies and Robinson (1963), and the second child mentioned by Ghadimi et al. (1961) show no such speech impairment.

La Du, Howell, Jacoby, Seegmiller, Sober, Zannoni, Canby, and Ziegler (1963) discussed possible mechanisms of selective speech involvement, and they found a short auditory memory in their two cases in the presence of normal hearing. The fact that our patient was thought to be deaf at the age of 9 months is of interest in this context.

Recurrent infections have been found by Ghadimi et al. (1961), Berlow et al. (1965), Davies and Robinson (1963), and by ourselves, the infection mainly involving the respiratory tract. Only the description of further cases will determine whether this is significant.

At least 7 out of the 23 cases have an IQ greater than 80 , but the proportion of patients with histidinaemia who have normal intelligence is probably greater than this as it is the retarded child who is investigated for metabolic disorders.

Delayed bone age is not a feature in most cases though it has been found by Auerbach et al. (1962) and Berlow et al. (1965) as well as by us. It is difficult to account for the epiphysial maturation that occurred in our patient while he was on a low histidine diet, as this was associated with a decrease in his height centile, unless the delayed bone age was due to his anaemia.

Anaemia was present in the patient described by Davies and Robinson (1963), but whereas ours responded to oral iron, in their patient no response was obtained to iron and folic acid, a blood transfusion being necessary.

Our patient is small, his height and weight lying on the 10th centile. Auerbach et al. (1962), Andrews, Crosby, and Angel (1962), Davies and Robinson (1963), and Clarance and Bowman (1966), have also noted this, while the patients described by Ghadimi et al. (1961), La Du et al. (1963), Shaw, Boder, Gutenstein, and Jacobs (1963), and Berlow et al. (1965), have been of normal size.

$\mathrm{La} \mathrm{Du}$ states that the birthweight is usually normal, but we feel that the low birthweight for gestational age of our patient and four others, in the 9 instances where this is stated, may be significant (Davies and Robinson, 1963; La Du et al., 1963; Auerbach et al., 1962).
Histidine metabolism. The absence of skin histidase in the child reported here agrees with the findings of Zannoni and $\mathrm{La} \mathrm{Du}$ (1963), Holton, Lewis, and Moore (1964), and Clarance and Bowman (1966) in a total of four cases. However, Woody et al. (1965) described three sibs in whom skin histidase was normal, and in whom they postulated the absence of liver histidase as the most likely explanation of their findings, though liver histidase activity was not estimated. They suggested that a significant amount of histidine could be metabolized by the skin histidase and that patients who possess the enzyme might be expected to have lower tissue and plasma histidine levels, and to excrete less imidazole-pyruvic acid. Our patient does not support this hypothesis, in that, though he had no skin histidase activity, the increase in plasma histidine was only moderate and there was no easily detectable increase in imidazole compounds even after a histidine load. It seems unlikely that the enzyme in the stratum corneum could be responsible for the breakdown of much histidine, and one must postulate other mechanisms to explain the wide range of biochemical expression of the disease. Obviously the levels of amino acid in the body will vary with the dietary intake and also with the ability to handle histidine by other pathways. If one excluded the production of imidazole-pyruvic acid, the known metabolic routes (Fig. 1) do not offer much scope for this; but an important factor in producing the variation in biochemical severity may be the wide range for the clearance of amino acids by the kidney. Recent observations for histidine (J.B.H., unpublished) show a fivefold difference from the lowest to the highest result. This degree of variation would cause a wide range of plasma histidine levels in patients, though the load of histidine to be excreted may be similar.

Family studies. The occurrence of low skin histidase activities in both the mother's and father's families fits an autosomal recessive pattern of inheritance which has been postulated for histidinaemia (La Du et al., 1963). Conflicting results in parents (we found a low skin histidase in the father and normal activity in the mother) are frequently encountered in attempts to detect heterozygotes. Zannoni and La Du (1963) found, similarly, a low skin histidase in the father and a normal result in the mother, while Holton (1965) found very low levels in both parents of a histidinaemic child.

The histidine load test, in contrast, was completely normal in the father while in the mother the twohour plasma histidine concentration was more than two standard deviations above the mean value in 10 
controls. This test has also met with variable success (Shaw et al., 1963; Holton et al., 1964; Ghadimi, Partington, and Hunter, 1962; Andrews et al., 1962). As an additional test, $\mathrm{La} \mathrm{Du}$ et al. (1963) measured FIGLU excretion after a histidine load and found this to be reduced in both parents compared to normal controls. Measuring the histidine/FIGLU ratio in urine after a histidine load should constitute a sensitive method of detecting a reduction in histidase activity.

Waisman (1967) found increased plasma histidine concentrations of $4 \cdot 1$ and 4.8 at birth and 5 days, respectively, in an unaffected sib of a child with histidinaemia, though the amino acid level was normal at 1 month. It is of interest that the younger brother of our patient has a similar high histidine value of 4.5 at 5 days, but this subsequently became normal. It is possible that the tendency to have increased histidine levels in the neonatal period is an expression of the heterozygous state.

Low histidine diet. It is difficult to connect the improvement in bone age of our patient with the falling off of his height on the centile chart while on a low histidine diet. It is possible that his delayed bone age was due to anaemia and that correction of this caused epiphysial maturation. During this time his weight had remained on the 10th centile and plasma amino acid analysis gave no clue as to the cause of his poor growth.

The low histidine diet did not have any significant effect on the level of plasma histidine. Holton (1964) reported a fall to normal histidine levels in a histidinaemic child using a similar diet and with an intake of $32-38 \mathrm{mg}$. histidine $/ \mathrm{kg}$. day. It may be that the amount of histidine given to our patient was not low enough to affect tissue histidine levels, but to have reduced the intake of normal foods more would have provoked outright rebellion from all concerned.

There is some evidence that it becomes impossible to control the histidine level by dietary means in older children, since La Du et al. (1963) found that putting their 5-year-old boy on $90 \mathrm{mg}$. histidine a day for 4 days had little effect on histidine excretion and none on plasma histidine levels. This is supported by the original observations of Rose, Haines, Warner, and Johnson (1951) that histidine is inessential in adults, though Snyderman, Boyer, Roitman, Holt, and Prose (1963) showed clearly that it was essential for growth and positive nitrogen balance in infants from 2 weeks to 7 months of age.

\section{Summary}

An 18-month-old boy, presenting with convul- sions, was shown to have histidinaemia after an increased histidine spot had been found on a urinary amino acid chromatogram. He was small with a delayed bone age and iron-deficient anaemia, but speech and development were within normal limits.

The plasma histidine has been consistently raised but, unlike the majority of reported cases, the urinary ferric chloride and 'Phenistix' tests were negative, except transiently after a histidine load. There was no detectable increase in imidazole compounds on a chromatogram, even after the histidine load.

The diagnosis was confirmed by the absence of FIGLU in the urine after a histidine load, the absence of skin histidase activity, and the absence of sweat urocanic acid.

His response to a low histidine diet is described, there being no significant reduction in plasma histidine levels and, possibly, a slowing down of growth. The place of histidine as an essential amino acid is discussed.

Family studies showed that his parents and other members of the family were heterozygous for the abnormal gene, thus confirming that histidinaemia is an example of autosomal recessive inheritance.

We would like to thank Dr. John Apley for permission to publish this case, Dr. Leonard Arthur for the initial investigations, Mr. Neville Jones for the psychological assessments, and Mr. N. A. Small and Mr. G. R. Moore for technical assistance. Laboratory investigations were supported by a grant from the Medical Research Council.

\section{REFERENCES}

Andrews, B. F., Crosby, P. F., and Angel, C. R. (1962). Histidinemia: a new metabolic disorder (abstract). Sth. med. F. (Bgham, Ala.), 55, 1326.

Auerbach, V. H., DiGeorge, A. M., Baldridge, R. C., Tourtellotte, C. D., and Brigham, M. P. (1962). Histidinemia: a deficiency in histidase resulting in the urinary excretion of histidine and imidazolepyruvic acid. F. Pediat., 60, 487.

Baldridge, R. C., and Greenberg, N. (1963). A method for the determination of histidine in blood. F. Lab. clin. Med., 61, 700.

Barger, G., and Stewart, C. P. (1926). $\quad \beta$-Iminazolyl-4 (or 5)-pyruvic acid. F. Pharmacol. exp. Ther., 29, 223-226.

Berlow, S., Arends, R., and Harries, C. (1965). Studies in histidinemia. f.-Lancet, 85, 241.

Clarance, G. A., and Bowman, J. K. (1966). A further case of histidinaemia. Brit. med. F., 1, 1019.

Davies, H. E., and Robinson, M. J. (1963). A case of histidinaemia. Arch. Dis. Childh., 38, 80.

Ghadimi, H., Partington, M. W., and Hunter, A. (1961). A familial disturbance of histidine metabolism. New Engl. $\mathcal{F}$. Med., 265, 221.

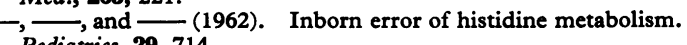
Pediatrics, 29, 714.

Holton, J. B. (1964). In First Meeting Abstracts, Federation of European Biochemical Societies, London, p. 117.

- (1965). Skin L-histidine ammonia-lyase activity in the family of a child with histidinaemia. Clin. chim. Acta, 11, 193.

—, Lewis, F. J. W., and Moore, G. R. (1964). Biochemical investigation of histidinaemia. $\mathcal{F}$. clin. Path., 17, 671. 
La Du, B. N. (1966). Histidinemia. In The Metabolic Basis of Inherited Disease, ed. J. B. Stanbury, J. B. Wyngaarden, and D. S. Fredrickson, 2nd edn., p. 366. McGraw-Hill, New York. , Howell, R. R., Jacoby, G. A., Seegmiller, J. E., Sober, E. K., Zannoni, V. G., Canby, J. P., and Ziegler, L. K. (1963). Clinical and biochemical studies on two cases of histidinemia. Pediatrics, 32, 216.

Lewis, F. J. W., and Moore, G. R. (1962). Detection of formiminoglutamic acid in urine without histidine loading. Lancet, 2, 359.

McKendrick, T. (1962). Sweat sodium levels in normal subjects, in fibrocystic patients and their relatives, and in chronic bronchitic patients. ibid., 1, 183.

Rose, W. C., Haines, W. J., Warner, D. T., and Johnson, J. E. (1951). The amino acid requirements of man. II. The role of threonine and histidine. F. biol. Chem., 188, 49.
Shaw, K. N. F., Boder, E., Gutenstein, M., and Jacobs, E. E. (1963). Histidinemia (abstract). F. Pediat., 63, 720.

Smith, I. (1958a). Chromatographic Techniques, p. 50. Heinemann, London.

- (1958b). ibid., p. 144.

Snyderman, S. E., Boyer, A., Roitman, E., Holt, L. E., Jr., and Prose, P. H. (1963). The histidine requirements of the infant. Pediatrics, 31, 786.

Waisman, H. A. (1967). Variations in clinical and laboratory findings in histidinemia. Amer. F. Dis. Child., 113, 93.

Woody, N. C., Snyder, C. H., and Harris, J. A. (1965). Histidinemia. ibid., 110, 606.

Zannoni, V. G., and La Du, B. N. (1963). Determination of histidine $\alpha$-deaminase in human stratum corneum and its absence in histidinaemia. Biochem. f., 88, 160. 